\title{
TELETRABALHO COMO FATOR DE INCLUSÃO SOCIAL E DIGITAL EM EMPRESAS DE CALL CENTER/CONTACT CENTER
}

\author{
TELEWORK AS A FACTOR OF SOCIAL AND DIGITAL \\ INCLUSION IN CALL CENTER/CONTACT \\ CENTER COMPANIES
}

\author{
Recebido: 25-04-2013 \\ Aceito: 11-02-2014 \\ Álvaro Augusto Araújo Mello ${ }^{1}$
Silvio Aparecido Dos Santos ${ }^{2}$
Marcio Shoiti Kuniyoshi ${ }^{3}$
Marcos Antonio Gaspar
Edson Keyso De Miranda Kubo ${ }^{5}$
}

\section{RESUMO}

O teletrabalho é uma realidade cada vez mais presente nos países desenvolvidos, tendo sido experimentado por diferentes tipos de empresas. Esta pesquisa teve como objetivo compreender como e por que as empresas de call center e contact center utilizam o teletrabalho na prestação de serviços. As quatro empresas abordadas representam 92\% do universo de empresas prestadoras desse serviço no Brasil, por meio de teletrabalhadores residenciais. Utilizou-se o método de pesquisa quali-quanti, com a combinação do método de estudo de caso e o método survey. As conclusões da pesquisa revelaram que o teletrabalho residencial tem sido utilizado com muito equilíbrio. As razões do uso desta modalidade foram: redução de custos; aumento da produtividade; melhoria da qualidade de atendimento aos clientes; possibilidade de oferecer melhor qualidade de vida aos teletrabalhadores residenciais e portadores de deficiência, proporcionando-Ihes oportunidades de empregos com inclusão social e digital.

Palavras-chave: Teletrabalho. Flexibilidade do trabalho. Inclusão social. Inclusão digital.

\footnotetext{
${ }^{1}$ Possui graduação em Administração pela Universidade Federal do Ceará - UFC. Mestrado em Administração pela Fundação Getúlio Vargas - FGV. Atualmente é doutorando em Administração pela Universidade de São Paulo - USP. São Paulo, São Paulo, Brasi. E-mail: alvaro@beca-ework.com

${ }^{2}$ Possui graduação em Administração pela Universidade Estadual de Maringa - UEM. Mestrado em Administração pela Universidade Federal de Minas Gerias - UFMG e doutorando em Administração pela Universidade de São Paulo - USP. Atualmente é professor titular em Administração na Universidade de São Paulo. São Paulo, São Paulo, Brasil. E-mail: sadsanto@usp.br

${ }^{3}$ Possui graduação e mestrado em Administração pela Pontifícia Universidade Católica de São Paulo - PUC SP. Doutorado em Administração pela Universidade de São Paulo - USP. Atualmente é professor titular de Administração na Universidade Metodista de São Paulo. São Bernardo do Campo, São Paulo, Brasil. E-mail: mskun@usp.br

${ }^{4}$ Possui graduação em Administração pela Universidade Presbiteriana Mackenzie. Mestrado em profissional em Administração pela Universidade Cidade de São Paulo - UNICID. Mestrado em Administração pelo Centro Universitário Santanna. Doutorando em Administração pela Universidade de São Paulo - USP. Atualmente é professor da Universidade Nove de Julho - UNINOVE. São Paulo, São Paulo, Brasil. Email: marcos.antonio@uninove.br

${ }^{5}$ Possui graduação em Administração Pública pela Universidade Estadual Paulista - UNESP. Mestrado em Administração de Empresas pela Kobe University e doutorado em Administração pela Fundação Getúlio Vargas - FGV. Atualmente é professor de Administração na Universidade Municipal de São Caetano do Sul - USCS. São Caetano do Sul, São Paulo, Brasil. Email:
} 


\begin{abstract}
Telework is a reality more and more present in developed countries, having been tried by different kinds of companies. This research aimed to understand how and why companies of call center and contact center use telework to provide their services. The four companies covered represent $92 \%$ of the population of this service in Brazil, through residential teleworkers. The method of qualitative and quantitative study was used with a combination of the method of case study and survey. The research findings revealed that residential telework has been used with great balance. The reasons for the use of this modality were cost reduction, high productivity, customer services' quality improvement, the ability to offer better quality of life for residential and teleworkers with disabilities by providing them with job opportunities and social and digital inclusion.
\end{abstract}

Keywords: Telework. Flexwork. Social inclusion. Digital inclusion.

\title{
1 INTRODUÇÃO
}

O acirramento da competição no mercado brasileiro, a partir da abertura da economia, levou as empresas a adotarem novas estratégias e meios para aprimorar o relacionamento com seus clientes. Os serviços de call center e contact center próprios ou contratados de empresas especializadas têm sido uma das ferramentas utilizadas pelas organizações para melhorar a relação entre cliente e empresa.

Dados de 2009 revelam que este segmento de serviços de call center e contact center faturaram cerca de $\mathrm{R} \$ 23$ bilhões, sendo que $\mathrm{R} \$$ 8,798 bilhões são provenientes de operações por intermédio de atendimento realizado por empresas de call centers terceirizadas. Ao comparar estes resultados com os dados de 2008, cujo faturamento foi de cerca de R\$ 21 bilhões de faturamento total, sendo $\mathrm{R} \$$ 7,98 bilhões provenientes das operações terceirizadas, constata-se que o mercado cresceu e deve continuar crescendo. Um estudo de previsão de crescimento realizado pela E-Consulting (Antonelli, 2011) estima que até o final de 2011 o faturamento chegou a R\$ 26 bilhões. Os call centers e contact centers atuantes no Brasil competem com empresas concorrentes nacionais e buscam adotar estratégias, processos e procedimentos de trabalho que lhes permitam reduzir custos, aumentar seus índices de produtividade e, com isso, obter melhores desempenhos e lucratividade.

Sob esse contexto de competição acirrada, os gestores dos call centers e contact centers têm utilizado o teletrabalho como nova modalidade de trabalho. Por esta prática, os empregados destas empresas - atendentes de call centers e contact centers - podem executar suas tarefas fora dos domínios da própria empresa, de forma remota e, na maioria das vezes, no local de residência. Dentro deste contexto, o teletrabalho é o serviço executado por um empregado a distância, em caráter contínuo, fora das instalações da empresa empregadora, utilizando-se do apoio e das facilidades tecnológicas de informação e comunicação (BERGUM, 2009).

Por ser uma nova realidade no ambiente de negócios de call center e contact center, o uso do teletrabalho não foi ainda objeto de pesquisa nestas empresas. Assim, a questão-problema que este artigo pretende responder é: COMO e POR QUE as empresas de call center e contact center estão usando o teletrabalho?

Não obstante, como objetivos específicos, buscou-se ainda: verificar as forças propulsoras e restritivas à implantação deste sistema de trabalho na opinião dos atores (gestores de empresas e teletrabalhadores) envolvidos no processo. 


\section{REFERENCIAL TEÓRICO}

\subsection{Breve histórico do teletrabalho}

O universo do trabalho foi alterado pelo uso intensivo destas tecnologias de informação e de comunicação (TICs). Por exemplo, na Europa, desde a década de 1990, constatou-se o aumento do contingente de pessoas empregadas nas tarefas relacionadas com a produção, transmissão e gerenciamento de informações. Mais de $50 \%$ dos postos de emprego, nesta região, estavam relacionados com o setor da informação (E-WORK, 2002). Deste contingente de empregos oriundos deste setor, $80 \%$ das vagas foram criadas por pequenas empresas do setor de informações e serviços. Mesmo nos setores primário e secundário, o maior percentual do valor provém do processamento de informação relacionada à sociedade do conhecimento.

O teletrabalho e suas modalidades aparecem, neste contexto, como uma das novas formas de trabalho. Alguns autores descrevem o fenômeno de crescimento do uso de teletrabalhadores de informação como "o de encontro simbólico da transição da sociedade industrial para a sociedade de informação" (MELLO; SANTOS, 2010, p. 12). De fato, o uso do teletrabalho vem ganhando espaço nas organizações de diferentes ramos e setores. A intenção desta pesquisa é conhecer como esta modalidade de trabalho está sendo usada nas empresas de call center e contact center.

De acordo com o cruzamento de pesquisas já realizadas, estima-se aproximadamente dez milhões de teletrabalhadores no Brasil. Pesquisa do jornal O Estado de S. Paulo (2008) cita 10,6 miIhões de teletrabalhadores no país, a Sociedade Brasileira de Teletrabalho e Teleatividades - Sobratt (2009) indica a existência de 9,9 milhões desses profissionais e o Portal E-Gov/UFSC (2011) sugere algo em torno de 10 milhões de pessoas. Os teletrabalhadores atuam em todos os setores e em diferentes áreas, onde se incluem as seguintes categorias de profissionais (SOBRATT, 2009):

a. os formais, informais, empregados ou por conta própria, autônomos, liberais, em tempo integral, parcial, complementar e eventual;

b. faixa etária que vai dos 18 aos 60 anos, com utilização de acesso à internet de uma vez por semana a uma vez por dia, considerando-se a utilização de desktops, notebooks, handhelds, smartphones, com acesso discado e/ou banda larga.

Conforme o estudo "2009 Microsoft SMB Insight Report", quase metade das empresas brasileiras $(49,6 \%)$ acredita que o número de trabalhadores remotos vai aumentar em 2009. 0 índice é menor do que o registrado nas pequenas e médias empresas (PMEs) do Canadá (72\%), Estados Unidos (69\%) e Reino Unido (63\%), mas está bem acima do percentual de organizações da França com a mesma crença (24\%) (MICROSOFT, 2009).

\subsection{Teletrabalho e seus conceitos}

O teletrabalho é um tipo de configuração de contrato de trabalho que estabelece as condições para que o trabalhador possa executar as atividades remotamente, ou seja, fora das instalações da empresa empregadora. A maioria das pessoas associa teletrabalho ao termo 'trabalho à distância'. Existem outros termos que qualificam este tipo de trabalho, tendo como base o local onde ele se desenvolve. Alguns exemplos de termos correlatos são: trabalho em casa (home office), trabalho por meio de telecommuting, telework (teletrabalho em inglês), trabalho por internet (e-work), trabalho flexível e, por fim, trabalho remoto (LIMBURG, 2002). 
O Centro de Teletrabalho e Teleformação de Carreira de Relações do Trabalho da Universidade de Buenos Aires define teletrabalho como:

O modo de trabalhar utilizando as tecnologias de informação e de comunicações (TIC) que pode ser realizado à distância, fora do ambiente onde se encontra o empregador, de forma total ou parcial, podendo ainda realizar-se em relação de dependência ou de forma autônoma. Considera-se ainda como qualquer forma de substituir as viagens relacionadas com o trabalho por tecnologias da informação (como telecomunicações e computadores); levar o trabalho para os trabalhadores ao invés de levar os trabalhadores para o trabalho (BOIAROV, 2009, p. 1).

No entanto, existem outras definições e interpretações do teletrabalho e, em algumas delas, a exigência de um acordo formal não é mencionada, como nos estudos de Shin, Sheng; Higa (2000); Baruch (2001) e Bailey e Kurland (2002). Observa-se também que Hertel, Geister e Konradt (2005) mencionam o teletrabalho como uma forma simples de novos métodos de trabalho, onde até mesmo o trabalho presencial em call centers é incluído (COMMISION OF THE EUROPEAN COMMUNITIES - CEC, 2005). Já Hanhike e Gareis (2004) incluem também o trabalho por conta própria, a cooperação à distância, escritórios remotos, outsourcing e offshore.

Alguns pesquisadores tais como Huws, Korte e Robinson (1990), Qvortrup (1998), Bakke e Julsrud (1999), Baruch (2001), Skamedal (2004) e Bergum (2009) argumentaram que não existe uma única definição de teletrabalho amplamente aceita. Porém, esses autores também reconheceram que, em um nível mais geral, são consideradas algumas características básicas do teletrabalho, apontadas, por exemplo, nos trabalhos desenvolvidos por Olson (1982), Huws (1988), Huws, Korte e Robinson (1990), Korte e Wynne (1996). Tais estudos concordam que três características principais são frequentemente usadas para enquadrar o domínio do teletrabalho:

a. É regulada por algum tipo de acordo formal;

b. É um trabalho que é feito a distância da sede, por um empregado ou autônomo;

c. Faz uso das TIC para apoiar o trabalho que é realizado à distância.

Para Igbaria e Guimarães (1999), bem como Dugal e Roy (2002), há várias razões para explicar a quantidade cada vez maior de empresas e trabalhadores que estão aderindo ao teletrabalho: a acelerada evolução da portabilidade dos equipamentos eletrônicos, o barateamento dos computadores, o aumento dos custos de aluguel de áreas corporativas, a substituição do trabalhador administrativo pelo trabalhador do conhecimento, mudanças na estrutura familiar, necessidade de ser flexível para permanecer competitiva, redução do absenteísmo, atração e retenção de empregados, atração de candidatos mais capacitados e, principalmente, a crença de que as organizações, os funcionários e a sociedade como um todo podem se beneficiar com o novo sistema.

Huws, Korte e Robinson (1990) explicitam que um trabalhador que transmite o resultado do seu trabalho, utilizando qualquer mídia - gravada e/ou impressa, é também considerado um teletrabalhador. Assim como, aquele trabalhador que utiliza um telefone celular para executar seu trabalho em caráter continuado. Nilles (1998) comenta que nem as telecomunicações e nem os computadores são necessários para teletrabalhar, pode existir trabalho remoto por outros meios.

Porém, Olszewski e Lam (1993) inserem a tecnologia no contexto do teletrabalho, na atualidade, como elemento vital à sua viabilização. Os autores entendem que o teletrabalho fazse viável por meio de ferramentas que permitem que o indivíduo esteja conectado à organização 
sem, entretanto, estar fisicamente presente nela. Segundo Perez, Sanches e Carnicer (2003), bem como Tremblay (2002), a ideia central repousa em duas bases: utilização das ferramentas de tecnologia da informação e comunicação e realocação do local de trabalho.

Para efeito desta pesquisa, o termo teletrabalhador é o mais adequado porque nas empresas de call center e contact center, as tecnologias de informação e comunicação já fazem parte do negócio da empresa.

Nilles (1998) procurou adotar outras dimensões para caracterizar o que é teletrabalho: tempo/distância, tecnologia, flexibilidade e informação/conhecimento.

Embora estas dimensões sejam importantes para caracterizar o teletrabalho, no contexto brasileiro, elas não estão claramente definidas porque ainda não existe uma legislação específica para regulamentar as atividades dessa natureza. Em função disso, bem como devido à falta de conceitos e definições padronizadas, há dificuldades em se conseguir estatísticas neste setor (TACHIZAWA; MELLO, 2003).

Por conseguinte, prevalece o conceito de que todo trabalho realizado fora das instalações da empresa, em caráter continuado, com dedicação parcial ou integral do tempo do empregado, seja teletrabalho. Cabe observar, também, que a legislação trabalhista brasileira e mundial está evoluindo para a regulamentação do teletrabalho como uma modalidade flexível de execução do trabalho, independente do local e do rígido horário de trabalho (KUGELMASS, 1996; BAHAMONDES, 2007; VIOR, 2009; FIOLHAIS, 1998).

No Brasil, o Projeto de Lei no 4.505/2008 (BRASIL, 2008) tem como objetivo regulamentar o teletrabalho, bem como conceituar e disciplinar todas as relações de trabalho envolvidas neste contexto. Um aspecto importante, tratado no referido projeto de lei, volta-se à contextualização do local de trabalho, ao explicitar que seja considerado, como tal, "a sede da empresa ou qualquer outro local onde normalmente ocorre a produção e/ou são normalmente esperados os resultados do exercício laborativo" (BRASIL, 2008, s.p.).

Em 2010, o projeto de lei em questão tramitou em caráter conclusivo, foi analisado e aprovado pela Comissão de Trabalho, de Administração e Serviço Público, e também pela Comissão de Constituição e Justiça e de Cidadania. Trata-se, portanto, de um Projeto de Lei que regulamentará, quando aprovado, o trabalho à distância (teletrabalho). Tal situação futura possibilitará a flexibilidade do desempenho das atividades diárias de trabalho, com benefícios para os teletrabalhadores que contarão com uma legislação que proteja esta modalidade de trabalho que, pelas evidências, já vem sendo utilizada de maneira formal ou informal no país.

Certo avanço, neste sentido, foi verificado com a promulgação da Lei 12.551/2011 (BRASIL, 2011), que reconheceu a figura do profissional teletrabalhador ao tê-lo equiparado ao trabalhador comum, sem, no entanto, regulamentar as peculiaridades específicas a atividade. A mesma lei alterou o artigo 6 으 da Consolidação das Leis do Trabalho (CLT) para equiparar os efeitos jurídicos da subordinação exercida por meios telemáticos e informatizados à exercida por meios pessoais e diretos.

Segundo Shaw (1996), há indícios de boas perspectivas para esta modalidade de trabaIho, na medida em que funciona como instrumento de flexibilização do trabalho, de competitividade do setor terciário e de fixação de negócios em áreas desfavorecidas.

\section{METODOLOGIA DA PESQUISA}

Esta é uma pesquisa exploratória, de natureza qualitativa e quantitativa. No que tange ao aspecto qualitativo, foi adotado o método de estudo de casos múltiplos, permitindo assim investigar, junto aos gestores, como tem sido o uso do teletrabalho pelas empresas de call center $\mathrm{e}$ 
contact center com empregados que trabalham fora das instalações da empresa, em posições remotas. Em termos da dimensão quantitativa, efetuou-se um survey (FREITAS et al., 2000) a partir das opiniões de teletrabalhadores, que atuam em suas residências, sobre o uso do teletrabalho pelas empresas de call center e contact center analisadas.

Segundo Yin (2003), estudos de casos podem envolver um caso único ou múltiplos casos e vários níveis de análise. Neste presente estudo, justifica-se a escolha do método do estudo de caso, por se tratar de uma investigação empírica de um fenômeno contemporâneo, envolvendo o teletrabalho dentro de uma realidade na qual os limites do fenômeno analisado não estão bem definidos.

Já em relação ao método survey empregado neste estudo, Yin (2003) recomenda o uso de tal expediente para orientar os esforços de pesquisa, na qual a finalidade do pesquisador seja explorar um fenômeno ainda pouco estudado no contexto em que se insere. Portanto, realizar uma pesquisa exploratória por meio de estudo baseado no método survey, significa coletar informações que permitam caracterizar, especificar melhor e descrever com mais propriedade os indivíduos e o fenômeno estudados (FREITAS et al., 2000).

Quanto aos critérios utilizados para a escolha das empresas, optou-se por organizações indicadas pela Associação Brasileira das Relações Empresa Cliente -ABRAREC,, nas quais o teletrabalho fosse executado por empregados formais, que trabalham em suas residências, executando processos operacionais de postos de atendimento de empresas de call center e contact center instaladas em estados das regiões Sul e Sudeste do Brasil. Com base no uso destes critérios e a partir da acessibilidade e conveniência dos pesquisadores junto às organizações indicadas, foram escolhidas seis empresas. Entretanto, duas empresas foram descartadas em função do término recente das atividades em regime de teletrabalho, em seu ambiente operacional. Dessa forma, restaram quatro empresas, doravante chamadas de Alpha, Beta, Gama e Omicron. Esta nomenclatura foi empregada de modo a preservar o nome real das empresas analisadas.

Eisenhardt (1989) sugere não existir uma quantidade ideal de casos em estudos desenvolvidos no campo das ciências sociais aplicadas. Entretanto, devido principalmente à disponibilidade de recursos e tempo, o número entre quatro e dez casos usualmente atende aos objetivos dos pesquisadores.

A pesquisa de campo foi realizada em duas etapas. Primeiramente foi aplicado um roteiro de entrevista semiestruturada aos gestores das empresas pesquisadas, buscando dados acerca da identificação dos gestores e da empresa, bem como informações sobre o teletrabalho desenvolvido na organização. Foram entrevistados quatro diretores, um de cada empresa selecionada pelos pesquisadores.

Os quatro diretores, das empresas analisadas, foram contatados por meio de comunicação expedida pela ABRAREC, constituindo-se assim numa forma de melhorar o acesso às empresas. As entrevistas junto aos diretores ocorreram nas próprias empresas, visando evitar deslocamentos dos respondentes. As entrevistas duraram entre 35 minutos e $1 \mathrm{~h} 15 \mathrm{~min}$., com tempo médio de duração de 52 minutos.

Numa segunda etapa, foi aplicado um questionário, enviado em formato eletrônico, aos teletrabalhadores com vínculo empregatício nas empresas analisadas, considerando-se apenas os profissionais que estavam envolvidos com a execução de atividades por meio do teletrabalho e em posições de atendimento instaladas em suas casas. Somente foram pesquisados teletrabaIhadores residenciais, componentes de uma amostra de respondentes caracterizada como empregados nas empresas estudadas.

O questionário aplicado junto aos respondentes teletrabalhadores continha a seguinte estrutura: a) seis questões acerca da identificação da empresa e do perfil do respondente, b) cinco questões para a caracterização do teletrabalho desenvolvido, c) 24 assertivas acerca de forças propulsoras do uso do teletrabalho, d) doze assertivas acerca de forças restritivas do uso do 
teletrabalho e, por fim, e) onze assertivas sobre as contribuições do uso do teletrabalho. Os três últimos blocos, do questionário eletrônico, apresentavam aos respondentes uma escala do tipo Likert de cinco pontos, variando entre 'discordo totalmente' e 'concordo totalmente'.

A escolha dos teletrabalhadores pesquisados na etapa quantitativa, viabilizada pelo survey, deu-se a partir de uma listagem com 150 trabalhadores que operavam em suas residências, conforme indicação dos diretores das quatro empresas selecionadas. Obteve-se um retorno de 64 questionários integralmente respondidos, constituindo-se assim a amostra validada considerada nesta pesquisa.

\section{APRESENTAÇÃO E ANÁLISE DOS RESULTADOS}

Nos próximos tópicos serão apresentados e analisados os casos das empresas, elaborados com base nas informações coletadas por meio de entrevistas personalizadas, questionários eletrônicos e outras informações extraídas de fontes secundárias: relatórios institucionais das empresas mencionadas, sítios eletrônicos e outros documentos oficiais que abordavam as experiências e o uso do teletrabalho, nestas empresas. Os diretores e gestores do programa de teletrabalho foram entrevistados pessoalmente. Tendo por base estas informações, foram redigidos os casos das empresas que utilizam o teletrabalho, a seguir apresentados e analisados.

\subsection{Análise e discussão dos dados da pesquisa}

As atividades mais executadas pelos teletrabalhadores que operam posições de atendimento residencial para as empresas de call center e contact center pesquisadas foram a realização de cobranças de clientes inadimplentes e vendas para clientes atuais e potenciais. Os teletrabalhadores residenciais executavam diariamente estas atividades em três, dentre as quatro empresas pesquisadas, conforme se constatou na época da realização da coleta de dados desta pesquisa nas empresas.

A modalidade de teletrabalho está subordinada à figura de gerentes, em todas as empresas estudadas, e esses estavam subordinados a algumas das diretorias funcionais das empresas, variando a função da diretoria de empresa para empresa. Embora o gestor tenha um vínculo hierárquico com uma das diretorias foi constatado que, o gerenciamento do teletrabalho necessita de um mecanismo gerencial que permita envolver representantes de várias áreas funcionais. Por esta razão, as empresas adotam um comitê ou equipe multidisciplinar para assessorar na gestão operacional do teletrabalho.

Todavia a modalidade de teletrabalho residencial envolve pessoas e, em alguns casos, pessoas com deficiência que necessitam de treinamento profissional e atenção mais qualificada, observou-se com singularidade que, somente, numa das empresas, dentre as pesquisadas, esta atividade estava subordinada à diretoria de talentos, conhecida mais comumente como unidade gestora de recursos humanos da empresa.

Em termos das razões pelas quais as empresas usam o teletrabalho, três dos quatro gestores das empresas de call e contact center pesquisados, apontaram que a busca por redução de custos era, na opinião deles, a razão principal do uso desta modalidade de trabalho residencial. Em segundo lugar, os gestores apontaram a busca pelo aumento da produtividade e qualidade de serviços de atendimento como razões para adoção do teletrabalho.

A terceira razão apontada pelos gestores para o uso do teletrabalho em residências pelas empresas pesquisadas foi, na ótica e opinião deles, a necessidade de atendimento das exigências da Lei 8.213/91, que define cotas mínimas de oferta de emprego para pessoas com deficiência em relação ao contingente total de empregados atuantes em cada empresa. A quarta 
razão, segundo a opinião dos gestores da modalidade de teletrabalho pesquisados, que motivou o uso do teletrabalho residencial pelas empresas estudadas, é que estas verificaram na oferta de postos de trabalho residencial para pessoas portadoras de deficiências uma oportunidade para por em prática um programa de responsabilidade social. Esta iniciativa viabilizou a incorporação destas pessoas ao mercado de trabalho, promovendo a inclusão social dos mesmos. Cabe ressaltar que estas pessoas, cuja maioria é de origem humilde, por intermédio deste tipo de trabalho acabam por ter a possibilidade de dispor, em sua residência, de um computador com acesso a Internet, o que lhe garante também a inclusão digital.

Em termos de acompanhamento e mensuração do desempenho dos trabalhadores, que operam em postos de atendimento de serviços de call center e contact center em suas residências, os gestores entrevistados informaram que o indicador de mensuração mais utilizado é a verificação da presença online, que comprova a disponibilidade e a prontidão do colaborador no posto de atendimento residencial. Esta disponibilidade é verificada também pelos índices de rotatividade e de absenteísmo, os quais mensuram os movimentos de entradas e saídas de teletrabalhadores do quadro das empresas e, também, das faltas aos postos residenciais.

A produtividade dos teletrabalhadores é acompanhada pelo índice de produtividade. Este índice é calculado em função da meta estabelecida, que define a quantidade de atendimentos que são desejáveis por dia, em comparação com a quantidade efetivamente realizada, durante cada jornada. Estes dados são computados pelo próprio sistema, com as informações dos atendimentos realizados, que ficam gravados na memória da plataforma que ele opera. Em termos de similaridade, todas as empresas pesquisadas utilizavam indicadores semelhantes de produtividade.

Outra similaridade entre as práticas de mensuração e acompanhamento do desempenho dos teletrabalhadores residenciais foi o uso, pela maioria das empresas, de um índice para mensurar e acompanhar a qualidade de vida dos teletrabalhadores em relação à execução de seu trabalho.

Em termos de identificação das forças propulsoras do uso do teletrabalho pelas empresas pesquisadas, segundo opinião dos gestores do teletrabalho, destacaram-se forças de natureza legal, sócio institucional e tecnológica. A necessidade de cumprimento das exigências da Lei de Cotas de empregados com deficiência foi apontada como uma das forças legais que levam as empresas a adotar o teletrabalho, cujas posições de atendimento eram operadas por seus empregados em suas próprias residências. Em relação às forças propulsoras de natureza tecnológica, foi constatado pelo depoimento dos gestores, que todas as empresas possuíam ou adquiriram tecnologias baseadas em sistemas de telecomunicações e informática, que permitiam o monitoramento e o gerenciamento de todas as atividades executadas pelo teletrabalhador residencial, da mesma forma como ocorre com aquelas supervisionadas pelos gestores no ambiente presencial, na sede da empresa.

É curioso notar que, as organizações abordadas têm por missão institucional capacitar pessoas com deficiência para serem empregadas por outras empresas, para que estas possam cumprir as exigências da Lei de Cotas. Neste caso, as forças propulsoras de natureza institucional e social foram: cumprir a missão da empresa e suprir outras empresas, com a oferta de profissionais com deficiência para serem empregados, facilitando desta forma que as demais empresas tenham condições de atender a exigência legal da Lei de Cotas de empregar um percentual de pessoas com deficiência em relação ao contingente total de empregados que possui. Outra singularidade observada, em uma das empresas, foi que altos executivos pleitearam que a empresa adotasse a modalidade de teletrabalho para que eles pudessem, depois que esta modalidade fosse ofertada, candidatar-se a trabalhar, pelo mesmo em tempo parcial, em suas respectivas residências.

Em relação à identificação de forças restritivas do uso do teletrabalho residencial pelas empresas de call center e contact center, os gestores apontaram que a dificuldade de contratar 
pessoas com deficiências em idade produtiva para o teletrabalho residencial é muito grande. Em todas as empresas esta força restritiva decorrente da falta de pessoas interessadas no mercado dificulta o uso mais intensivo desta modalidade de trabalho. Duas razões contribuem para que esta força se manifeste. Uma delas é a carência da qualificação profissional das pessoas com deficiência e a outra é o fato da maioria estar recebendo o benefício de prestação continuada (BPC) do governo como ajuda de autos- sustentação, pela sua condição de deficiente e, por isto, evita aceitar ofertas de emprego formal, temerosa com a possibilidade de perder o benefício e posteriormente, por qualquer motivo, o emprego.

Outra força restritiva do teletrabalho pelas empresas, segundo os gestores pesquisados, é a inexistência de uma legislação específica para regular esta modalidade de trabalho. Embora já exista projeto de lei em tramitação no Congresso, até o momento a lei não foi aprovada. A Consolidação das Leis do Trabalho (CLT) é aplicada em alguns itens, tais como: jornada e piso salarial, porém não atende às especificidades do teletrabalho residencial. Por exemplo, as exigências dos acordos sindicais em convenções coletivas, como o pagamento de vale transporte, marcação de ponto e vale refeição, dificultam o cumprimento pelas empresas, que usam esta modalidade de ofertar trabalho nas próprias casas dos empregados. A força restritiva de natureza mercadológi$\mathrm{ca}$, que restringe o uso do teletrabalho nas empresas, apontada pelos gestores, é proveniente do comportamento de algumas empresas (clientes) contratantes dos serviços de call center e contact center relutarem na contratação dos serviços, quando tomam conhecimento que estes serão operados por teletrabalhadores em posições de atendimento instaladas em suas próprias residências. A razão deste comportamento relutante das empresas é a preocupação com a segurança das informações que serão manuseadas pelo teletrabalhador em sua residência. Como exemplo, as informações cadastrais de clientes, e especialmente de clientes inadimplentes consideradas sigilosas. Esta força se manifestou como restritiva em três empresas pesquisadas. Duas destas empresas, inclusive, deixaram de utilizar teletrabalhadores residenciais por razões desta força restritiva de origem mercadológica, sendo, portanto, um aspecto comum na maioria dos casos estudados.

Em termos de contribuições - ganhos e benefícios - obtidas pelas empresas, pelos teletrabalhadores e pela sociedade, em decorrência da empresa ter usado o teletrabalho operado em posições de atendimento residencial, para prestação de serviços de call center e contact center, verificaram-se alguns aspectos em comum nas falas dos gestores, notadamente presentes em três das empresas estudadas. Tais similaridades voltaram-se ao fato das empresas buscarem, em primeiro lugar, auferir ganhos de produtividade e, em segundo lugar, a redução de custos empresariais. Em termos dos ganhos e benefícios obtidos pelo teletrabalhador, decorrentes do uso do teletrabalho pela empresa, observou-se uma similaridade de opiniões dos gestores pesquisados, ou seja, tanto a empresa quanto os teletrabalhadores obtiveram ganhos, como: 1) reduções de gastos com compras de roupas necessárias para ida e vinda ao trabalho e a dispensa de comparecer no dia a dia de trabalho na sede da empresa; 2) ganhos obtidos em termos de melhoria de qualidade de vida pelo fato de realizarem o trabalho em casa.

Para a sociedade como um todo, na opinião dos gestores entrevistados, os ganhos obtidos em decorrência do uso de teletrabalho pelas empresas, foram: a oferta de novos postos de trabalho para as pessoas e, de forma especial, para aquelas com deficiências físicas, idosas e aposentadas.

Quanto às perspectivas de continuidade ou não do uso da modalidade de teletrabalho pelas as empresas de call center e contact center, três empresas, entre as quatro cujos casos foram estudados, pretendem dar continuidade ao uso desta modalidade. Os gestores de uma das empresas entrevistadas informaram que por mudança do foco estratégico de negócios, não continuará usando esta modalidade de trabalho residencial. Destaca-se que duas empresas, que 
inicialmente foram selecionadas na amostra de estudo, desistiram do uso desta modalidade, ainda durante a realização desta pesquisa.

Estas duas empresas haviam sido consideradas, na amostra, para efeito de estudos de casos a serem pesquisados. Porém, desistiram do uso do teletrabalho antes da concretização desta pesquisa. Uma delas desistiu de operar com teletrabalho alegando que o retorno financeiro, deste tipo de atividade, não comtemplou as expectativas dos dirigentes. A outra decidiu não usar mais esta modalidade de trabalho residencial devido aos elevados custos de manutenção. Por esta razão, optou por tornar-se provedora de tecnologia e de modelo de gestão do teletrabalho, para outras empresas, ou seja, deixou de ser uma operadora para tornar-se uma vendedora de sistemas de gestão e de tecnologia de operação de call center e contact center para outras empresas, encerrando, desta forma, a sua operação própria.

\subsection{Análise estatística do uso do teletrabalho nas empresas de call center e contact center estudadas}

Após a fase de planejamento e coleta de dados, obteve-se um número de 64 respostas válidas ( $n=64$ ) e utilizadas para as análises estatísticas, o que representa aproximadamente $42,6 \%$ da população. Assim, conforme verificado nas respostas, será apresentado o fenômeno do teletrabalho nas empresas de call center e contact center. O perfil dos teletrabalhadores pesquisados é constituído em sua maior parte por jovens profissionais, na faixa dos 20 e 30 anos, correspondendo a $42,18 \%$ dos respondentes, seguido dos profissionais entre 30 e 40 anos, aproximadamente $34,39 \%$, e os mais experientes, acima de 40 anos com representatividade de $23,43 \%$.

Quanto ao gênero, estado civil e nível educacional, constatou-se que esta é uma profissão predominantemente feminina, correspondendo a $62,5 \%$ dos respondentes, formado pela maioria de pessoas solteiras, com 62,5\% e 75 dos respondentes concluíram, no mínimo, o ensino médio.

Outra revelação importante diz respeito ao estado civil, demonstrando que a maioria dos teletrabalhadores é formada por jovens solteiros, o que corrobora com a conjetura de que, grande parte destes profissionais teve sua iniciação profissional por meio do teletrabalho - primeiro emprego, e que provavelmente ainda buscam a consolidação da carreira e o desenvolvimento profissional. Em relação ao tempo médio de permanência na função, observa-se que estes profissionais ainda têm pouco tempo de experiência, média de 2 anos e quatro meses.

Questionados sobre as principais razões que os levaram a escolher a profissão de teletrabalhador, evidenciou-se o seguinte: os problemas de limitações físicas e nova experiência no trabalho, conforme demonstrado na Tabela 1.

Tabela 1- Razões da escolha pela profissão

\begin{tabular}{lll}
\hline & Frequência & $\%$ \\
\hline Problemas físicos & 34 & 53,1 \\
Nova experiência no trabalho & 29 & 45,3 \\
Flexibilidade de horário & 27 & 42,2 \\
Redução de perda de tempo no trânsito & 27 & 42,2 \\
Maior tempo com a família & 25 & 39,1 \\
Possuir espaço físico & 20 & 31,3 \\
Independência & 18 & 28,1 \\
Aumento de produtividade & 16 & 25
\end{tabular}




\begin{tabular}{lll}
\hline & Frequência & $\%$ \\
\hline Outros & 6 & 9,6 \\
Melhor salário & 3 & 4,7 \\
\hline
\end{tabular}

Fonte: dados da pesquisa.

Dentre as razões menos importantes, aponta-se a busca de melhores salários. Isso se explica pelo fato de a maioria destes profissionais serem jovens ingressantes no mercado de trabalho ou profissionais com deficiências físicas preocupados, principalmente, com a oportunidade do emprego e não com o salário propriamente dito. $O$ teletrabalho pode ser considerado uma alternativa para o acesso ao mercado de trabalho, para as pessoas com deficiência. Além das motivações profissionais, verifica-se que existem razões pessoais e psicológicas, que fizeram com que estes profissionais escolhessem a profissão de teletrabalhadores, de acordo com a tabela 2.

Tabela 2 - Medidas descritivas das razões de ser teletrabalhador

\begin{tabular}{lllll}
\hline & Mín. & Máx. & $\bar{x}$ & $s$ \\
\hline Sinto-me melhor trabalhando em casa & 1 & 5 & 4,45 & 0,946 \\
Estou mais próximo a minha familiar & 1 & 5 & 4,42 & 1,124 \\
Gerencio melhor, em casa, a minha agenda de trabalho & 1 & 5 & 4,33 & 1,02 \\
Consigo me concentrar melhor e ser mais produtivo em casa & 1 & 5 & 4,28 & 1,199 \\
Sinto-me mais motivado por trabalhar de forma remota & 1 & 5 & 4,15 & 1,209 \\
Lido melhor com a ansiedade sobre as pressões do trabalho & 1 & 5 & 4,08 & 1,154 \\
Sinto ter mais autonomia para executar minhas atividades de profissio-- & 1 & 5 & 4,07 & 1,167 \\
nais & & & 3,44 & 1,381 \\
Prefiro ser controlado à distância pelo meu supervisor & 1 & 5 & 3,12 & 1,439 \\
Relaciono-me melhor com os colegas de trabalho à distância & 1 & 5 & 3,12 \\
\hline
\end{tabular}

Fonte: dados da pesquisa.

Entre as principais razões e vantagens que motivaram a escolha desta profissão, segundo a opinião dos respondentes, destacam-se: a) sentir-se melhor por trabalhar em casa; b) estar próximo à família; c) concentrar-se melhor no trabalho; d) gerenciar de forma eficiente e eficaz sua agenda; e) organizar as suas atividades e tarefas.

Sem dúvida, os teletrabalhadores podem conciliar de forma mais equilibrada a sua vida profissional com a vida pessoal, quando comparado ao trabalho tradicional. Uma motivação está vinculada aos tipos de atividades exercidas por estes profissionais e as condições necessárias para o bom desempenho. Isto porque as atividades executadas pelos atendentes de call center e contact center, muitas vezes, exigem foco, concentração ou, pelo menos, menor distração e organização para o consequente bom atendimento aos clientes e alcance das metas estabelecidas. Outra razão está relacionada à necessidade de autonomia e flexibilidade para gerenciar o trabalho e a vida pessoal. Para ambos os aspectos mencionados, de acordo com as respostas auferidas, os teletrabalhadores lidam melhor com a ansiedade sobre as pressões do trabalho e acabam por ter mais autonomia para executar as atividades profissionais.

A técnica de análise fatorial (HAIR et al., 2005) ajudou a confirmar os resultados previamente auferidos com a Estatística Descritiva. Observou-se, respeitando-se o critério de maior eigenvalue e variância explicada pelas variáveis, a emergência de três fatores que explicam a preferência pelo teletrabalho: Fator 1-Busca de autonomia e flexibilidade; Fator 2-Concentração 
e produtividade; Fator 3- Preferência pelo relacionamento à distância.

De acordo com a Análise Fatorial (AF) o Fator 1 - Busca de Autonomia e Flexibilidade tem o maior poder de explicação, com aproximadamente $28 \%$ das razões e motivos que o levaram a ser teletrabalhador. A variável de maior peso neste fator é referente à assertiva "Sinto-me mais motivado por trabalhar de forma remota" $(0,803)$. Ao analisar em conjunto com as demais variáveis, percebe-se a existência de uma maior preocupação com a proximidade da família, lidar melhor com a ansiedade, necessidade de autonomia, e o fato de sentir-se melhor trabalhando de casa, o que se supõe a necessidade da busca de autonomia e flexibilidade pelos teletrabalhadores.

O segundo fator identificado pela $A F$, com $23 \%$ do total da variância explicada, foi o fator Concentração e Produtividade. A variável que tem o maior peso neste fator é baseada na assertiva "Gerencio melhor, em casa, a minha agenda de trabalho" $(0,902)$. Entretanto, outra variável importante neste fato é baseada na assertiva: "Consigo me concentrar melhor e ser mais produtivo em casa" $(0,804)$. Assim, percebe-se que neste fator existe um direcionamento para a obtenção de ganhos de produtividade, por meio da concentração no trabalho.

E o terceiro fator, com $18 \%$ do total da variância explicada, foi Preferência pelo Relacionamento a Distância. A variável de maior peso neste fator foi baseada na assertiva "Prefiro ser controlado à distância pelo meu supervisor" $(0,864)$, seguida da variável baseada na assertiva "Relaciono-me melhor com os colegas de trabalho à distância" $(0,703)$. Assim, baseado nestas assertivas, pressupõe-se a preferência pelo relacionamento à distância.

Além da AF, procedeu-se também a análise de cluster (HAIR et al., 2005) que chegou a delimitação de três grupos, que ajudam a esclarecer o perfil do teletrabalhador, descritos a seguir:

O cluster 1 - Jovens profissionais que buscam flexibilidade de horário e preferem trabaIhar em casa - é composto por indivíduos que têm, em média, 28 anos de idade. Os profissionais pertencentes a este agrupamento acreditam que a empresa utiliza o teletrabalho para reduzir os custos e usam esse contexto para alavancar a qualidade de vida.

O cluster 2 - Profissionais experientes com visão pragmática do uso do telebrabalho - é formado por indivíduos dentro da faixa de 37 anos de idade e com pouco tempo de experiência no teletrabalho. Os profissionais pertencentes a este agrupamento, quando comparado aos demais, mostram-se indiferentes às variáveis apresentadas - redução de custos, flexibilidade no trabalho, melhoria na qualidade de vida, possibilidade de empregar pessoas com deficiência, melhorar os serviços prestados aos clientes.

O cluster 3 - Adultos experientes e preocupados com a qualidade de vida - é o agrupamento formado por pessoas com média de idade de 45 anos, e que creem que a empresa de call center e contact center usa o teletrabalho como um meio de melhorar a qualidade de vida dos funcionários, bem como incluir pessoas com deficiência.

Em síntese, observou-se uma concordância das opiniões dos gestores com as opiniões do teletrabalhadores sobre os motivos, os fatores propulsores e restritivos da adoção do teletrabalho e as contribuições - ganhos e benefícios - advindas dos resultados desta survey. Além disso, os resultados desta survey foram ao encontro dos dados obtidos na pesquisa qualitativa, conduzida nas quatro empresas analisadas.

\section{CONSIDERAÇÕES FINAIS}

O presente trabalho teve como objetivo compreender COMO e POR QUE as empresas utilizam o teletrabalho na prestação de serviços de call center e contact center. Vale ressaltar que não foram constatadas diferenças marcantes, nas opiniões de gestores e de teletrabalhores, acer- 
ca de eventuais diferenças entre o trabalho presencial e o teletrabalho nesse tipo de atividade.

A principal razão que levou as empresas de call center e contact center analisadas a utilizarem o teletrabalho está, principalmente, voltada ao interesse dos altos executivos e presidentes das empresas estudadas. Estes gestores buscam oferecer uma nova alternativa de execução do trabalho, de forma mais flexível em relação ao tempo e localização, permitindo assim que seus funcionários executem suas atividades e tarefas, anteriormente realizadas somente na empresa, em suas residências, proporcionando maior equilíbrio entre a vida profissional e a vida familiar. Eles acreditam que o teletrabalho proporciona vantagens quanto à produtividade, minimização de custos e melhoria na qualidade dos atendimentos aos clientes das empresas contratantes dos serviços.

Em relação à identificação de forças propulsoras do uso do teletrabalho, pelas empresas pesquisadas, tendo por base as opiniões dos gestores e teletrabalhadores, foi possível concluir que algumas forças se destacaram: busca de redução de custos; busca da melhoria da produtividade; melhoria da qualidade do atendimento aos clientes finais das empresas contratantes; melhoria da qualidade de vida dos teletrabalhadores; busca de melhoria da imagem corporativa por meio do uso do teletrabalho, como atividade ligada a responsabilidade social, que possibilite a inclusão social e digital de pessoas com deficiência.

Quanto à identificação das forças restritivas do uso de teletrabalho, sob a ótica dos gestores e dos teletrabalhadores, que operam nas suas residências como empregados das empresas de call center e contact center, verificou-se que há obstáculos quanto à segurança da informação. Os desafios auferidos na pesquisa de campo são: a) empresas contratantes mostraram-se inseguras quanto à preservação do sigilo sobre as informações manuseadas pelos teletrabalhadores residenciais; b) escassez de mão-de-obra qualificada e com perfil adequado para a execução das atividades de teletrabalho residencial típicas de call center e contact center; c) falta de legislação trabalhista específica para regulamentar a atividade do teletrabalho no país; d) ausência da infraestrutura de comunicação nas regiões urbanas onde se localizam as residências de alguns teletrabalhadores; e) pelo fato de o teletrabalho ser uma função desempenhada na residência do teletrabalhador, este passa a ter pouco contato pessoal com os demais membros da equipe e a chefia, que atuam na sede da empresa, sendo que tal isolamento, sob a ótica do teletrabalhador, configura-se como um dificultador à sua ascensão profissional.

Observaram-se as seguintes contribuições advindas do teletrabalho: ganho de produtividade do teletrabalhador residencial quando comparado aos operadores tradicionais; ganho na imagem corporativa da empresa devido à atuação socialmente responsável, por meio da oferta da modalidade do teletrabalho para pessoas com deficiência e idosas; redução da rotatividade e do absenteísmo (ocorreu uma redução de licenças médicas, tratamentos clínicos e outros motivos de ausência); ganhos obtidos pelas empresas pesquisadas decorrentes da melhoria da qualidade de atendimento aos clientes; ganho na qualidade de vida dos teletrabalhadores devido à economia de tempo de deslocamento e redução de estresse decorrentes de menor exposição ao trânsito urbano; contribuição à diminuição de poluentes emitidos pelos veículos, redução do caos no trânsito, todos decorrentes da menor necessidade de deslocamento dos empregados até as sedes das empresas, ao contrário do que ocorre com o trabalhador na modalidade tradicional.

Respondendo à pergunta de pesquisa deste artigo, o que se concluiu é que, operacionalmente, a execução de atividades típicas de call center e contact center, por teletrabalhadores residenciais portadores ou não de deficiência física, é perfeitamente factível e viável. Apesar disso, o uso de teletrabalhadores nesse segmento de prestação de serviço é bastante restrito. Deve-se destacar que as quatro empresas de call center e contact center mencionadas, representam $92 \%$ do universo de empresas deste segmento que utilizam teletrabalhadores residenciais no país. 
A expansão do uso desta modalidade de trabalho é, entretanto, limitada por alguns aspectos (forças restritivas). Entre elas, destaca-se a insegurança jurídica pela inexistência de uma legislação especifica que regulamente a atividade dos teletrabalhadores remotos e residenciais. Outra limitação está relacionada ao comportamento das empresas contratantes (clientes) das prestadoras de serviço de call center e contact center estudadas. Esses clientes corporativos relutam em aceitar que as atividades de atendimento dos seus clientes finais sejam realizadas por teletrabalhadores que operam em suas residências. Existe a temeridade relacionada à possível perda, extravio ou vazamento de informações sigilosas sobre o cadastro ou a situação financeira da empresa e dos seus clientes. Sabe-se que o teletrabalhador residencial manuseia informações sigilosas. O teletrabalho é uma realidade recente e seu potencial uso, alertado pelos executivos entrevistados, pode se tornar uma prática de responsabilidade social da empresa, com vistas ao fortalecimento da de sua imagem corporativa.

Uma limitação do presente estudo volta-se ao reduzido número de casos estudados, não obstante a representatividade das empresas analisadas no contexto da prestação de serviços em call center e contact center no país. Outra limitação a ser mencionada diz respeito ao recorte transversal no tempo do estudo efetuado, uma vez que em outros momentos a realidade captada na pesquisa de campo poderia ser diferente. Há ainda de se evidenciar que os resultados auferidos por esta pesquisa, basearam-se nas opiniões dos respondentes, em que pesem quaisquer singularidades provenientes de suas experiências individuais.

Como sugestão para estudos futuros extensivos ou complementares a este, indica-se a possibilidade de analisar as características do teletrabalho desenvolvido por outras empresas, atuantes em diferentes ramos de atividade ou regiões do país. Também é possível indicar pesquisas comparativas acerca do teletrabalho desenvolvido em outros países, de modo a contribuir para a compreensão do estágio de evolução desta temática no mundo.

\section{REFERÊNCIAS}

ANTONELLI, V. Crise? Que crise? Anuário Brasileiro de Call Center e CRM - 2011. São Paulo: Padrão, 2011.

BAILEY, D. E.; KURLAND, N. B. A review ok telework research: findings, new directions, and lessons for thestudy of modern work.Journal of Organizational Behavior, v. 23, n. 4, p. 383-400, 2002.

BAHAMONDES, R. B. Teletrabajo para el Peru: hacia uma implementación juridica promotora. Universidad Privada de Tacna. Facultad de Derecho y Ciencias Políticas. Lima: FDCY, 2007.

BAKKE, J. W.; JULSRUD, T. E. Telework research: Setting the scene. Telektronikk, v. 95, n. 4, p. 4-9, 1999.

BARUCH, Y. The status of research on teleworking and an agenda for future research.
International Journal of Management Reviews, v. 3, n. 2, p. 113-29, 2001.

BERGUM, S. Management of teleworkers: managerial communication at a distance. Tukum Kauppakorkeakoulu - Turku School of Economics. Turku: Uniprint, 2009.

BOIAROV, S. Telecapacitados - Teletrabajo para la inclusión laboral de personas com discapacidad. Buenos Aires: El Cid, 2009.

BRASIL. Projeto de lei 4.505/2008. Brasília: Câmara dos Deputados, 2008. Disponível em: <http://www.camara.gov. $\mathrm{br} /$ proposicoesWeb/fichadetramitacao?id Proposicao $=420890>$. Acesso em: 05 set. 2013.

Lei 12.551/2011. Brasília: Presidência da República, 2011. Disponível em: <http://www.planalto.gov.br/ccivil_03/_ ato2011-2014/2011/lei/l12551.htm>. Acesso em: 06 set. 2013. 
COMMISIONOFTHEEUROPEANCOMMUNITIES - CEC. Collaboration at work: the 2005 report on new working environmental practices. Bruxelas: CEC, out./2005.

DUGAL, S.; ROY, M. H. Creating value through relationship building in a globalized marketplace. Journal of International Business and Entrepreneurship, v. 9, n. 1, p. 153-70, 2002.

E-GOV/UFSC - Portal de e-governo, inclusão digital e sociedade do conhecimento. Teletrabalho no Brasil: o exemplo da Gol (e quando chegará a nossa vez?). 2011. Disponível em: <http://www.egov.ufsc. br/portal/conteudo/not\%C3\%ADciateletrabalho-no-brasil-o-exemplo-da-gol-equando-chegar\%C3\%A1-nossa-vez>. Acesso em: 07 set. 2013.

EISENHARDT, K. M. Building theories from case study research. The Academy of Management Review, v. 14, n. 4, p. 532-50,1989.

JORNAL O ESTADO DE S. PAULO. Teletrabalho: uma solução para enfrentara insustentabilidade do trânsito em cidades como São Paulo. 2008. Disponível em: <http://www.gohome.com.br/ estadao-106-milhoes-de-teletrabalhadoresno-brasil/>. Acesso em07 set. 2013.

E-WORK 2001. Informe de situación de los nuevos métodos de trabajo en la economía del conocimiento. Commission Europea. Dirección General de la Sociedad de la Información. Bruxelas: E-Work, 2002.

FIOLHAIS, R. Sobre as implicações jurídicolaborais do teletrabalho subordinado em Portugal. Lisboa: IEFP, 1998.

FREITAS, H.; OLIVEIRA, M; SACCOL, A. Z.; MOSCAROLA, J. O método de pesquisa survey. Revista de Administração, v. 35, n. 3, p. 10512, jul./set. 2000.

HANHIKE, T.; GAREIS, K. Modelling e-work: Towards a better understanding of information technology's impact on workplaces and work locations. In: ANNUAL INTERNATIONAL LABOUR PROCESS CONFERENCE, 22th, Amsterdam. Proceedings... Amsterdam, ILPC, 2004, p. 1-19.

HAIR, J.; ANDERSON, R. E.; TATHAM, R. L.; BLACK, W. C. Análise multivariada de dados. 5 ed. Porto Alegre: Bookman, 2005.

HERTEL, G.; GEISTER, S.; KONRADT, U. Managing virtual teams: A review of current empirical research. Human Resource Management Review, n. 15, p. 69-95, 2005.

HUWS, U.; KORTE, W. B.; ROBINSON, S. Telework: towards the elusive office. Chichester: John Wiley \& Sons, 1990.

HUWS, U. Remote possibilities: some difficulties in the analysis and quantification of telework in the UK. In: KORTE, W. B.; ROBINSON, S.; STEINLE, W. J. Telework: present situation and future development of the new form of work organization. North-Holland, 1998, p. 61-76.

IGBARIA, M.; GUIMARÃES, T. Exploring differences in employee turnover intentions and its determinants among telecommuters and non-telecommuters. Journal of Management Information Systems, Armonk, v. 16, p. 147-64, 1999.

KORTE, W.; WYNNE, R. Telework penetration, potential and practice in Europe. Amsterdan: IOS Press, 1996.

KUGELMASS, J.; Teletrabalho: novas oportunidades para o trabalho flexível Seleção de funcionários, benefícios e desafios, novas tecnologias de comunicação. São Paulo: Atlas, 1996.

LIMBURG, D. Making telework a reality: a method for introducing a new way of working into an organization. Amsterdam: Twenty University Press, 2002.

MELLO, A. A. A.; SANTOS, S. A. dos. Telework and virtual organizations: some business practices in the context of Brazil. In: 2010's 
TELEWORK. Buenos Aires, 2010. Proceedings... Buenos Aires, Telework, 2010, p. 1-16.

MICROSOFT. 2009 Microsoft SMB insight rerport. Redmond: Microsoft, 2009.

NILLES, J. M. Managing telework: strategies for managing the virtual workforce. New York: John Willey \& Sons, 1998.

OLSON, M. H. Remote office work: changing work patterns in space and time. Communications of the ACM, v. 26, n. 3, p. 182-87, 1982.

OLSZEWSKI, P.; LAM, S. H. Can teleworking help to reduce traffic congestion in Singapore? In: TRANSASIA' 93 CONFERENCE, 1993, Cingapura. Procedings... Cingapura, set. 1993.

PEREZ, M. P.; SANCHEZ, A. M.; CARNICER, $P$. de $L$. The organizational implications of human resources managers' perception of teleworking. Personnel Review, Farnborough, v. 32, n. 6, p. 733-55, 2003.

QVORTRUP, L. From teleworking to networking. In: JACSON, P.; VAN DER WIELEN, $J$. M. Teleworking: international perspectives. Londres: Routledge, 1998, p. 21-39.

SHAW, L. A. R. Telecommute: go to work without leaving home. New York: John Wiley \& Sons, 1996.

SHIN, B.; SHENG, O. R. L.; HIGA, K. Telework: existing research and future directions. Journal of Organizational Computing and Electronic Commerce, v. 10, n. 2, p. 85-101, 2000.

SKAMEDAL, J. Telecommuting's implications on travel and travel patterns. Tese (Doutorado em Administração) - University of Linköping. Estocolmo, 2004.

SOBRATT - Sociedade Brasileira de Teletrabalho e Teleatividades. Quantos teletrabalhadores há no Brasil. 2009. Disponível em: <http:// www.sobratt.org.br/faq.html >. Acesso em: 28 jul. 2012.
TACHIZAWA, T.; MELLO, A. A. A. Estratégias empresariais e o teletrabalho: um enfoque na realidade brasileira. Rio de Janeiro: Campus, 2003.

TREMBLAY, D. Balancing work and family with telework? Organizational issues and challenges for women and managers. Women in Management Review. v. 17, n. 3-4, 2002.

VIOR, A. G. Teletrabajo, subordinación y dependencia laboral. Buenos Aires: Errepar, 2009.

YIN, R. K. Case study research: design and methods, applied social research methods series. 3 ed. Thousand Oaks: Sage Publications, 2003. 